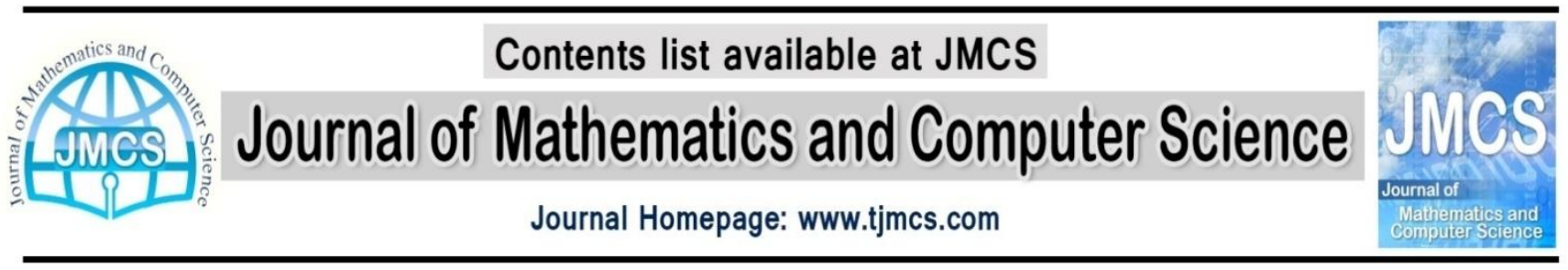

\title{
An Intelligent Estimator for Transient Overvoltages Study during Induction Motors Starting Alireza Sadoughi ${ }^{(1)}$, Iman Sadeghkhani ${ }^{(2)}$ \\ ${ }^{(1)}$ Department of Electrical Engineering, Malek-Ashtar University of Technology, Shahinshahr 115/83145, Iran \\ ${ }^{(2)}$ Department of Electrical Engineering, Najafabad Branch, Islamic Azad University, Najafabad 85141- 43131, Iran
}

Article history: sadoughi@mut-es.ac.ir; i.sadeghkhani@ec.iut.ac.ir (Corresponding Author)

Received October 2013

Accepted December 2013

Available online December 2013

\begin{abstract}
This paper deals with transient overvoltage phenomenon which is occurred during induction motors (IMs) starting. This power quality (PQ) disturbance can damage motors' dielectric insulation and affect the locally connected other loads. First, effective parameters on these overvoltages are identified. Then, an artificial neural network (ANN) is proposed to evaluate them. The most common structures, i.e. multilayer perceptron (MLP) and radial basis function (RBF) are adopted to train the ANN. The MLP structure is trained with the six learning algorithms, including backpropagation (BP), delta-bar-delta (DBD), extended delta-bar-delta (EDBD), directed random search (DRS), quick propagation (QP), and levenbergmarquardt (LM). The results show the effectiveness of proposed approach to predict accurate value of overvoltage peak. Based on performed comparison among all developed ANNs, it is proven that LM and EDBD algorithms have best performance for this goal.
\end{abstract}

Keywords: Induction motors, multilayer perceptron, radial basis function, transient overvoltages.

\section{Introduction}

The most common motor in various sections of the world is induction motor (IM) which is also called asynchronous motor [1-3]. They can be used not only in the industry (usually in three-phase form), but also in the household appliances (usually in single-phase form). Because of widely use of these motors, their operation must be studied comprehensively. Main advantages of this motor are [4]:

- It is robust

- It has simple and rugged construction

- It is reliable

- It is relatively cheap

- It requires little maintenance 
- It has wide range (from a few watts to values on the order of $10000 \mathrm{hp}$ )

- It has high efficiency and reasonably good power factor

- Its speed is nearly constant

- It has self-starting torque

In contrast, IM has following major disadvantages:

- Its speed control is not easy

- It has low power factor (lagging) in the lightly loaded condition

- It causes some power quality problems like high starting current, voltage sag, and transient overvoltages

Power quality (PQ) is a major issue in the electrical systems, which is found more importance in recent years due to increasing use of power electronic devices and sensitive loads [5-6]. Starting of large IMs causes several disturbances to the motor itself and affects the locally connected other loads [7]. Transient overvoltage during IM starting is one of the PQ disturbances and fully discussed in this paper. This overvoltage will cause the reactive component of the current inside to increase causing eddy current heating of the rotor and stress on the insulation. Its peak can reach two times of rated voltage, which may seriously harm the motors' dielectric insulation leading to subsequent failures [8]. As a result, this overvoltage should be evaluated properly to avoid its harmful effects.

This paper proposes an artificial neural network (ANN) to evaluate this overvoltage accurately. Timedomain simulations considering various system configurations consume a large amount of time and are not proper for considering various cases of IM starting. Developed ANNs in this paper help manufactures and operators to evaluate a variety of conditions and calculate the worst case of overvoltage peak during IM starting real time. This information help them to consider precautionary measures during both design and operation stages. The ANN is trained with the most commons structures and algorithms. Results of the studies shows that developed ANNs can estimate overvoltages peak with good accuracy.

The rest of the paper is organized as follows. The overvoltages caused by IM starting are discussed in Section 2. Section 3 proposes ANNs to evaluate overvoltages. Discussion is presented in Section 4. Finally, the paper is concluded in Section 5.

\section{Overvoltages during IM Starting}

One the major concerns during IM starting is occurrence of overvoltages as a result of switching procedures. Impedance mismatch between the motor and the long cable causes voltage reflection and thus overvoltages occur at motor terminal. Accurate estimation of this overvoltage plays a significant role for motor dielectric insulation and optimal design of $d v / d t$ filters [8-10].

\subsection{Study System Modelling}

The electrical section of induction machine is represented by a fourth-order state-space model and the mechanical section by a second-order system [11]. All electrical variables and parameters are referred to the stator. All stator and rotor quantities are in the arbitrary two-axis reference frame ( $d$ q frame). Usually, cables are modeled using series resistance and inductance and parallel capacitance 
in the distributed form or in the PI form [12]. In this paper, the model of Fig. 1 is adopted as connecting cable model.

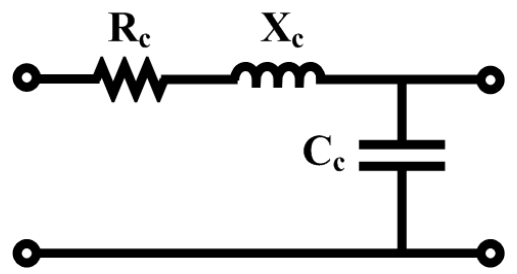

Fig. 1.Single-phase representation of adopted cable model.

\subsection{Study System Description}

Fig. 2 shows a sample circuit which is adopted to study overvoltages during IM starting. This system includes the induction motor KHV355-2 from VALIADIS company [13]. This motor is a 2 poles, $200 \mathrm{~kW}$ $(270 \mathrm{hp}), 3300 \mathrm{~V}$ induction motor. Parameters of this motor were calculated using no-load test, locked-rotor test, and DC test [14]. This motor is fully simulated using power system blockset (PSB), a MATLAB/Simulink-based simulation tool [15].

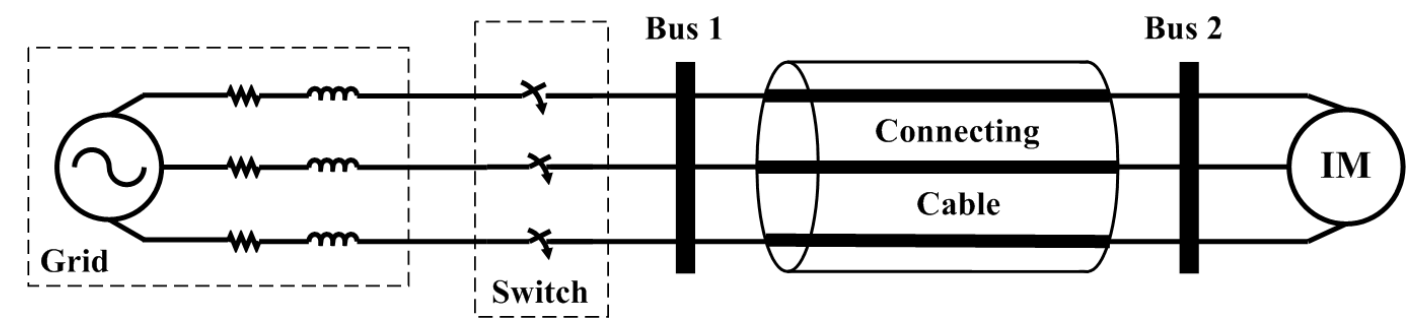

Fig. 2.Sample system for the overvoltage study.

Fig. 3 shows terminal voltage of IM during starting period. As shown in this figure, overvoltage peak can reach about 2 p.u. As mentioned before, long cable contributes to overvoltages significantly. Fig. 4 shows the result of the PSB frequency analysis at bus 2 . The magnitude of the cable impedance shows a parallel resonance peak around $600 \mathrm{~Hz}$. In the other hand, frequency spectrum of terminal voltage is also presented in Fig. 5. As shown in this figure, terminal voltage also has significant harmonic contents around $600 \mathrm{~Hz}$. It shows the effect of cable impedance on the overvoltage.

In practical system a number offactors affect the overvoltages peak. In this paper following parameters were considered:

- Supply voltage $(V)$

- Resistance of the connecting cable $\left(R_{c}\right)$

- Reactance of the connecting cable $\left(X_{c}\right)$

- Capacitance of the connecting cable $\left(C_{C}\right)$

- Stator reactance $\left(X_{/ s}\right)$ 
- Referred rotor reactance $\left(X_{/ r}^{\prime}\right)$

- Switching angle (S.A.)
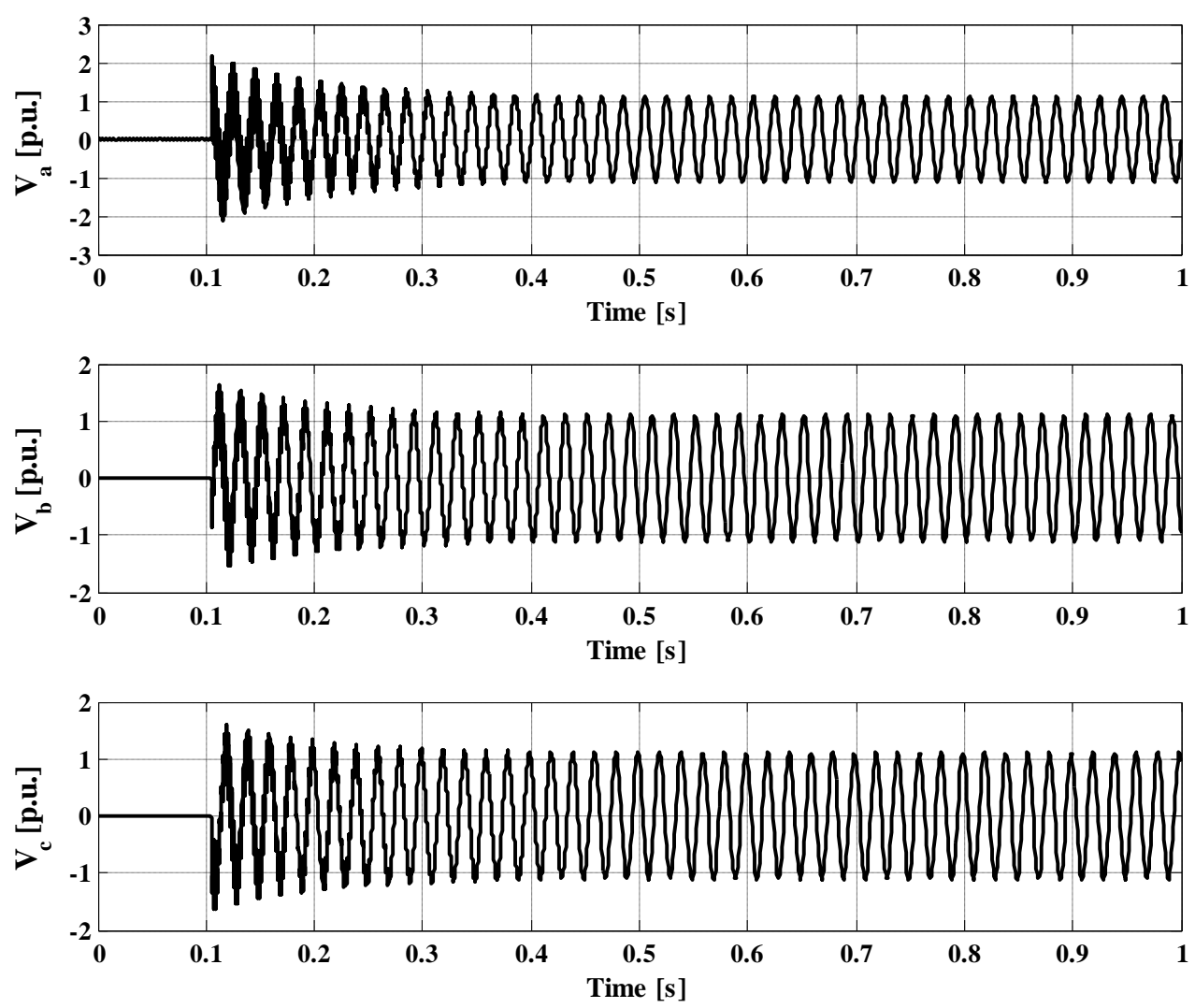

Fig. 3. Three-phase voltage at motor terminal (bus 2). IM starts at $\mathrm{t}=0.1 \mathrm{~s}$.

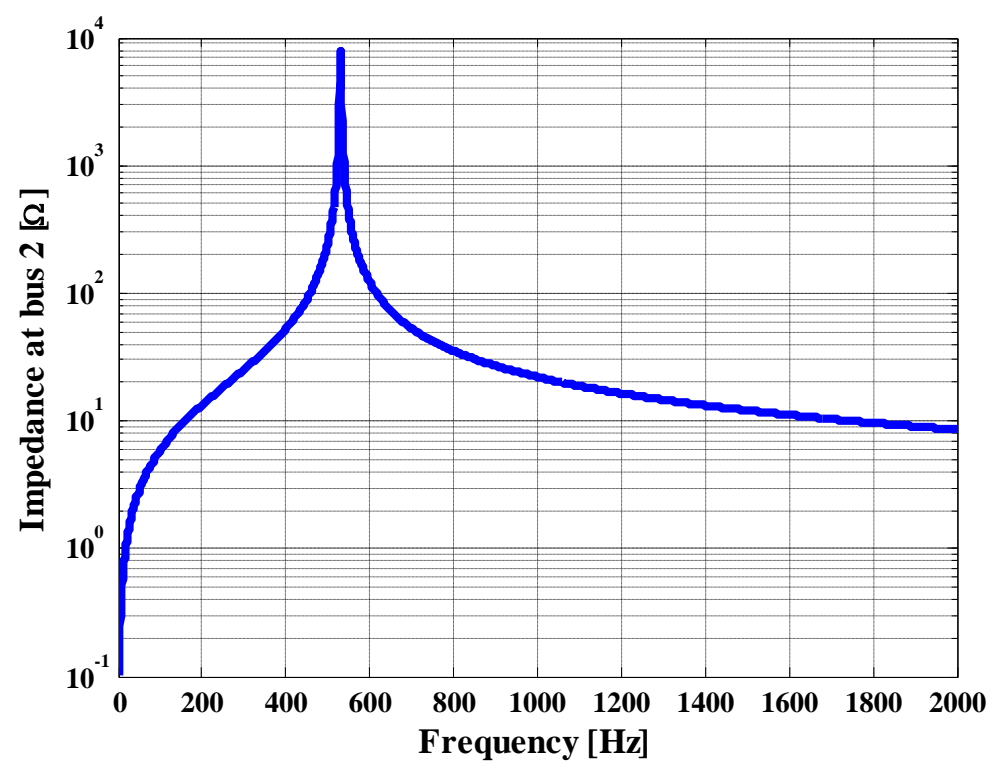

Fig. 4.Impedance at bus 2 . 


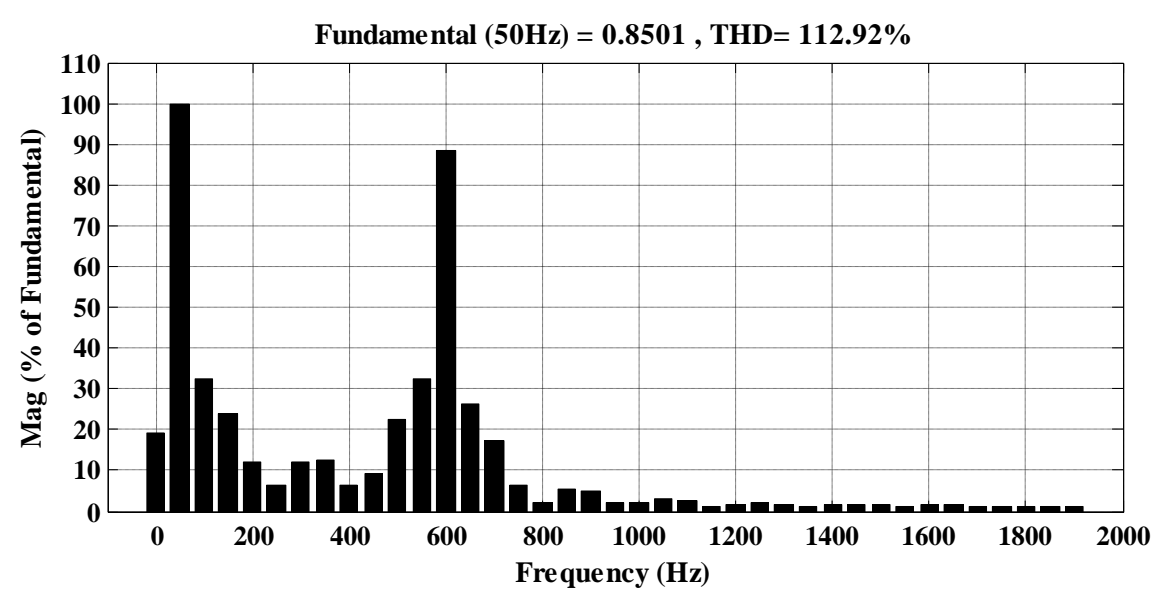

Fig. 5. Harmonic analysis of terminal voltage.

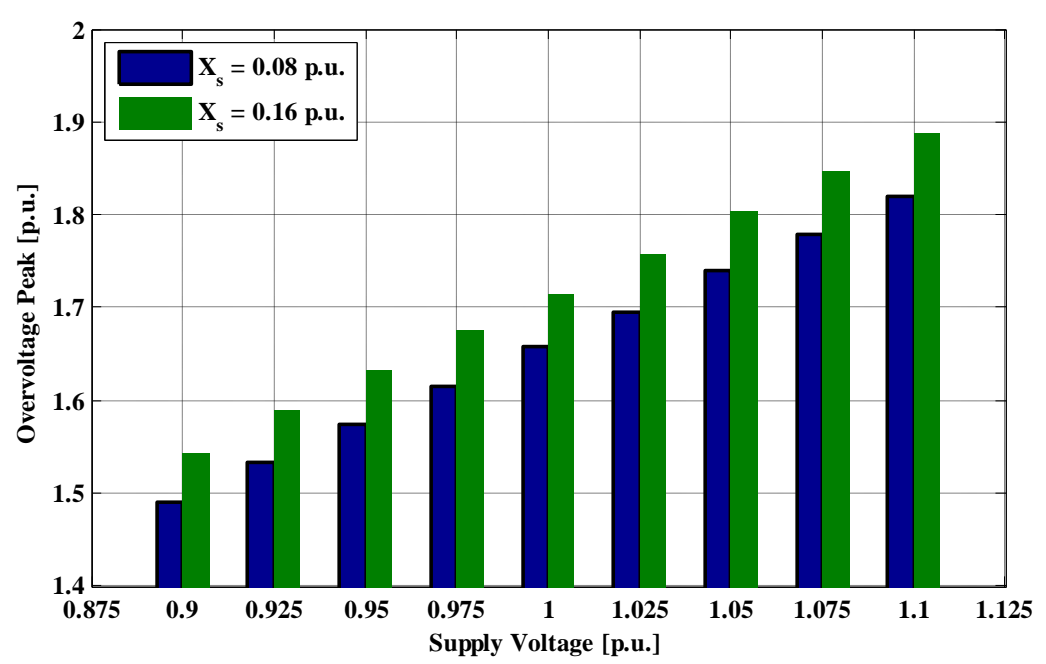

Fig. 6. Overvoltage peak as supply voltage while cable resistance 0.004 p.u., cable reactance 0.0188 p.u., cable capacitance $1 \mu \mathrm{F}$, referred rotor reactance 0.08 p.u., and switching angle $50^{\circ}$.

Effect of system and motor parameters on the overvoltage peak is investigated here. In this work, adopted overvoltage peak is the largest peak among all three phases to consider the worst case of overvoltage for every system configuration. First, Fig. 6 shows effect of supply voltage on the overvoltage peak at different stator reactance. As shown in this figure, value of this parameter affects overvoltage peak extremely. Effect of cable reactance on the overvoltage peak at different switching time is presented in Fig. 7. Also, Fig. 8 shows effect of switching time (angle) on the overvoltage peak at different referred rotor reactance. Unlike supply voltage and cable reactance, overvoltage peak has non-uniform behavior for increasing switching time. Moreover, effect of cable capacitance on the overvoltage peak at different cable resistance is presented in Fig. 9.

There are other parameters which are not considered here. Fig. 10 shows effect of stator and referred rotor resistance, magnetizing reactance, load torque, and total rotor and load inertia on the overvoltage peak. As shown in this figure, these parameters don't have significant effect on the overvoltage peak; thus they are not included in this analysis. 


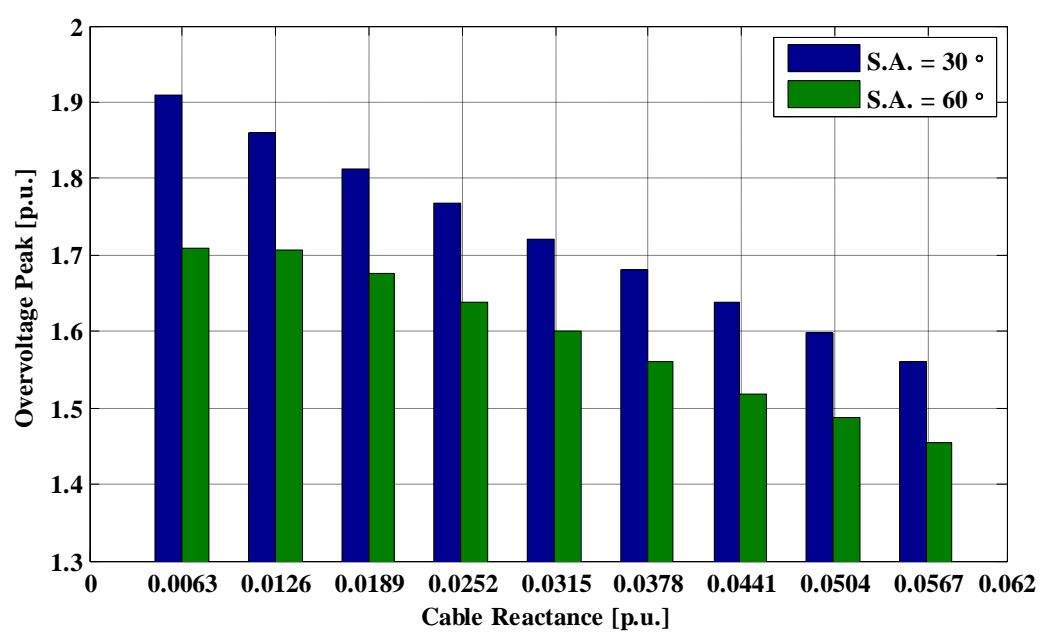

Fig. 7. Overvoltage peak as cable reactance while supply voltage 1 p.u., cable resistance 0.004 p.u., cable capacitance $10 \mu \mathrm{F}$, stator reactance 0.12 p.u., and referred rotor reactance 0.1 p.u.

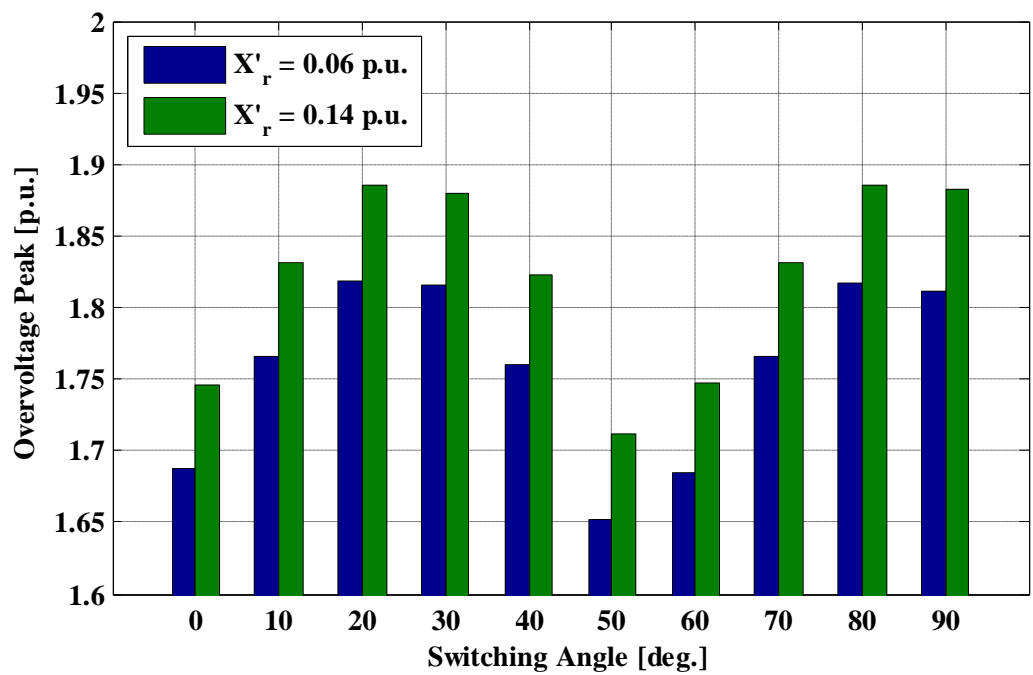

Fig. 8. Overvoltage peak as switching time while supply voltage 1.05 p.u., cable resistance 0.004 p.u., cable reactance 0.0251 p.u., cable capacitance $10 \mu \mathrm{F}$, and stator reactance 0.12 p.u.

\section{The Artificial Neural Network}

The various types of artificial neural networks (ANNs) are explained in the literature [16-24]. The most common structures of ANN are multilayer perceptrons (MLPs) and radial basis functions (RBFs) which are examples of feed-forward networks. In spite of being different networks in several important respects, these two neural network architectures are capable of accurately mimicking each other. These two structures are considered here to evaluate overvoltage peak. MLP is trained with six algorithms including back propagation (BP), delta-bar-delta (DBD), extended delta-bar-delta (EDBD), directed random search (DRS), quick propagation (QP), and levenberg-marquardt(LM). The $B P, D B D, E D B D, D R S, Q P$, and RBF are fully described in [16], and mathematical description of LM can be found in [25]. The basic structure of developed ANN is shown in Fig. 11. 


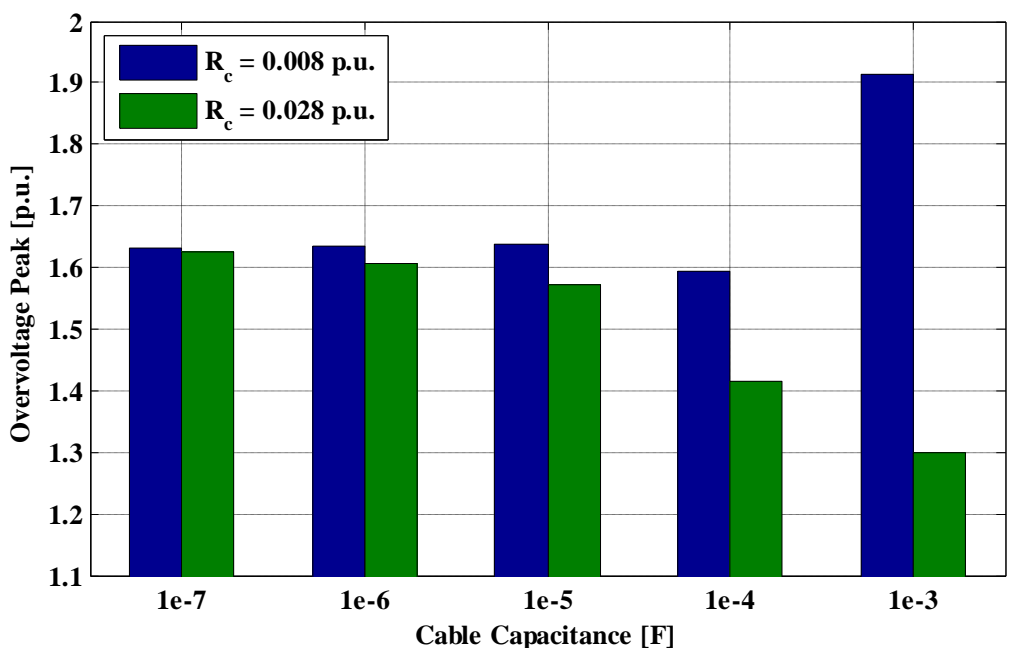

Fig. 9. Overvoltage peak as cable capacitance while supply voltage 1 p.u., cable reactance 0.0251 p.u., stator reactance 0.04 p.u., referred rotor reactance 0.1 p.u., and switching angle $75^{\circ}$.

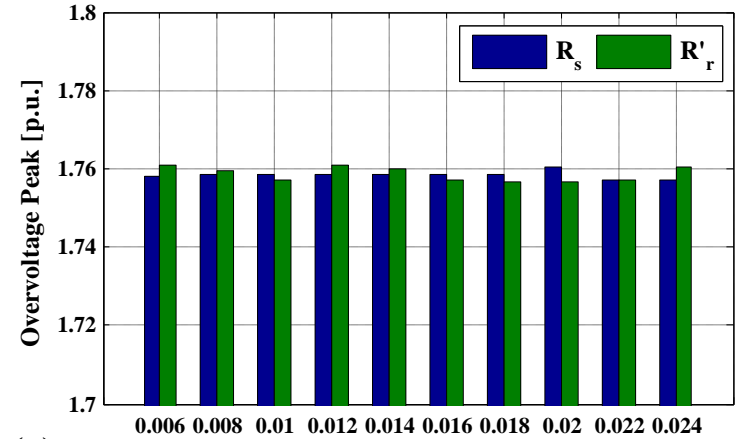

(a)
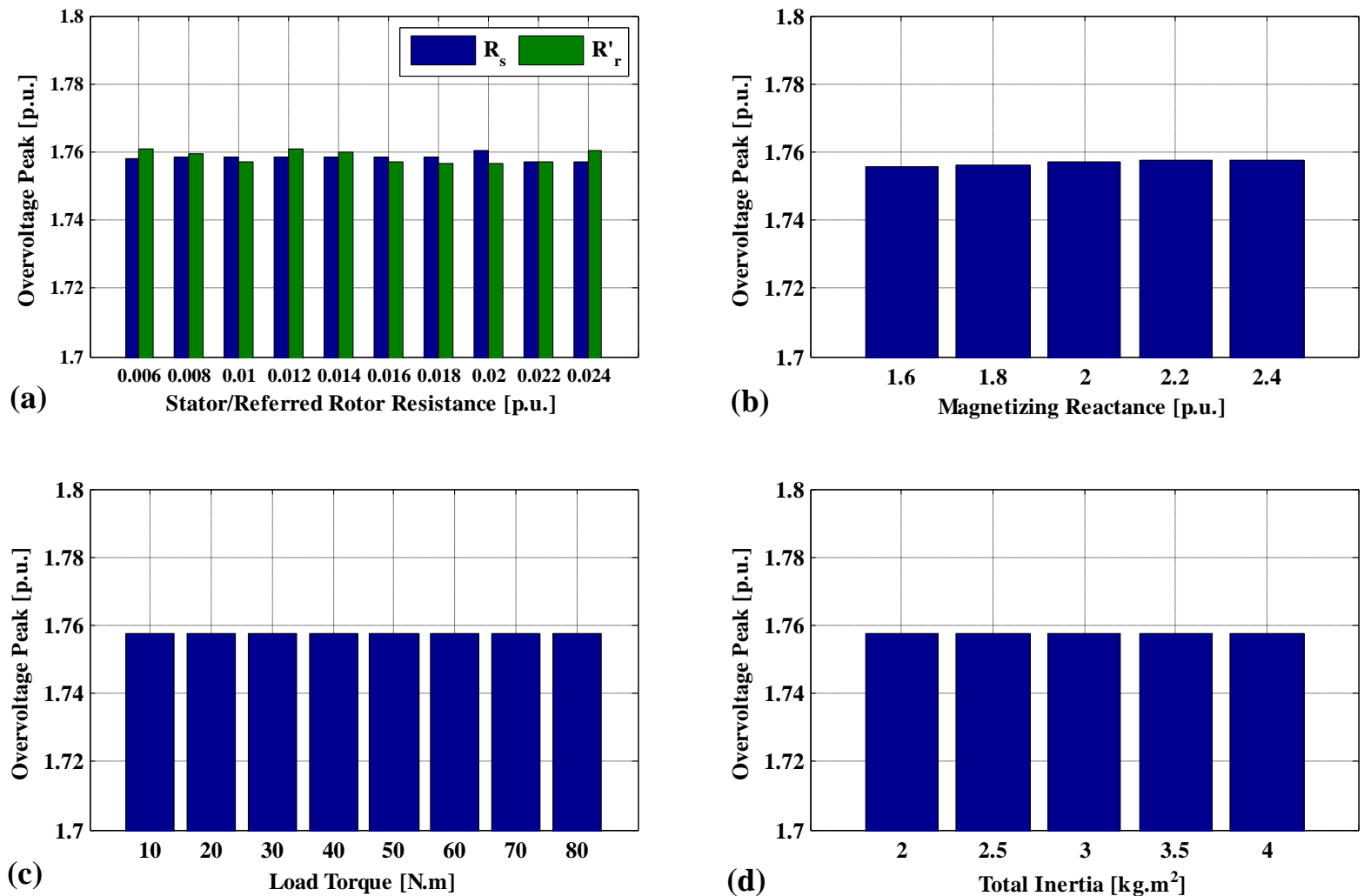

(d)

Total Inertia [kg. $\left.\mathrm{m}^{2}\right]$

Fig. 10. Overvoltage peak as (a) stator and referred rotor resistance, (b) magnetizing reactance, (c) load torque, (d) total inertia, while supply voltage 1.05 p.u., cable resistance 0.01 p.u., cable reactance 0.0188 p.u., cable capacitance $10 \mu \mathrm{F}$, stator reactance 0.08 p.u., referred rotor reactance 0.12 p.u., and switching angle $45^{\circ}$. 


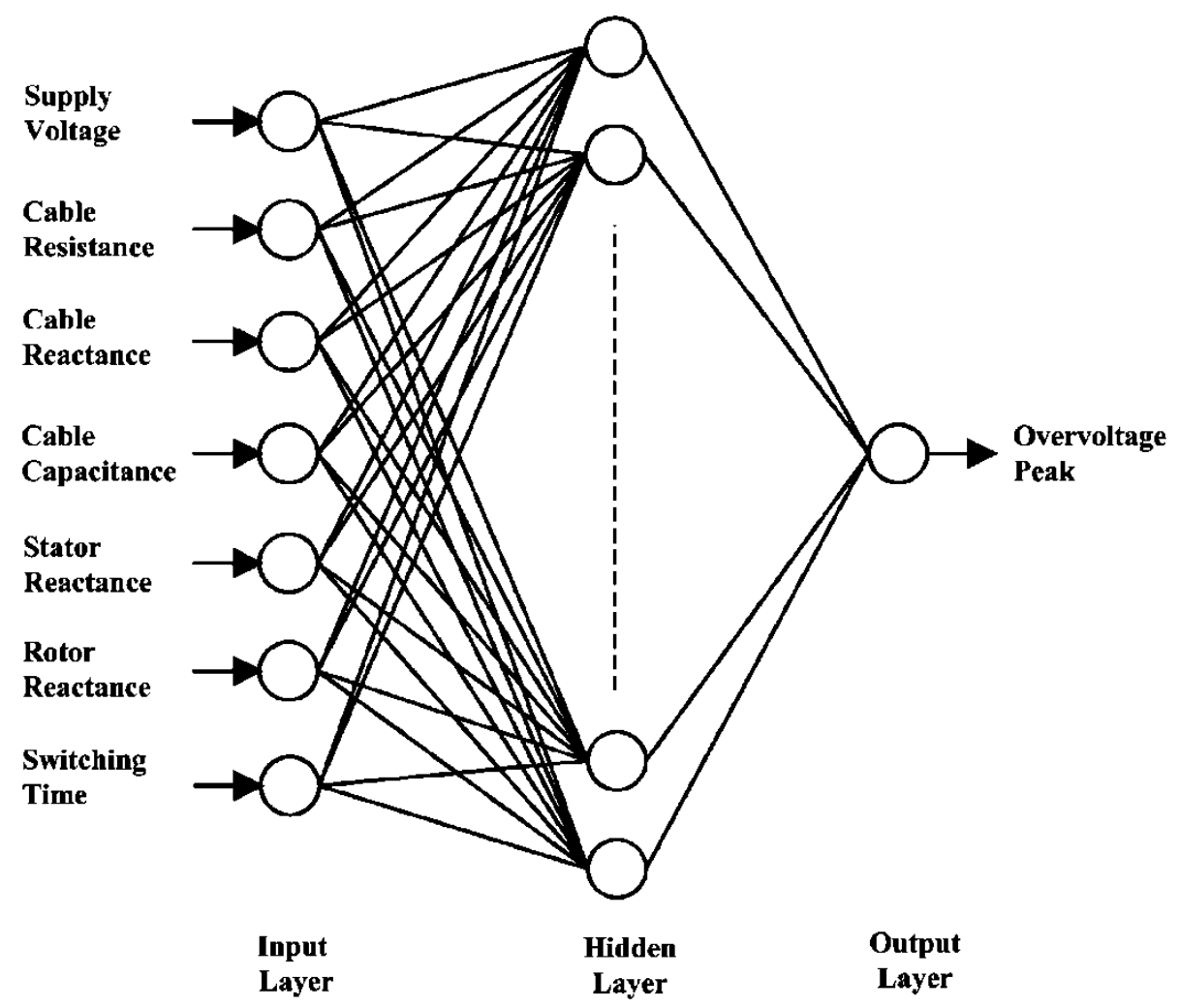

Fig. 11.Basic structure of developed artificial neural network.

\subsection{Training of Artificial Neural Network}

For an ANN training, first input and output parameters should be selected properly. In this work as shown in Fig. 11, supply voltage, cable resistance/reactance/capacitance, stator/referred rotor reactance and switching time are adopted as ANN output. In the other hand, overvoltage peak (the worst case among three phases) is selected as ANN unique output. For training process, different system configuration must be considered. Thus, ANN input parameters are varied in different steps (depend on the parameter) and associated overvoltage peak is calculated using PSB to create inputoutput patterns. These patterns form training and testing sets. $20 \%$ of these sets are randomly selected as training sets and other $80 \%$ of these sets are used for testing developed ANNs. Each ANN is trained with the goal of mean square error (MSE) 5e-5. Fig. 12 shows the training of neural network for developed ANNs. Specifications of developed ANNs are presented in Table 1.

Relative error is calculated by the difference of PSB output and ANN output:

$$
\operatorname{Er}_{\text {Relative }}(\%)=\frac{\left|O V_{\text {ANN }}-O V_{\text {PSB }}\right|}{O V_{\text {PSB }}} \times 100
$$

and absolute error is calculated as:

$$
\mathrm{Er}_{\text {Absolute }}=\left|\mathrm{OV}_{\mathrm{ANN}}-\mathrm{OV}_{\mathrm{PSB}}\right| \text {, }
$$




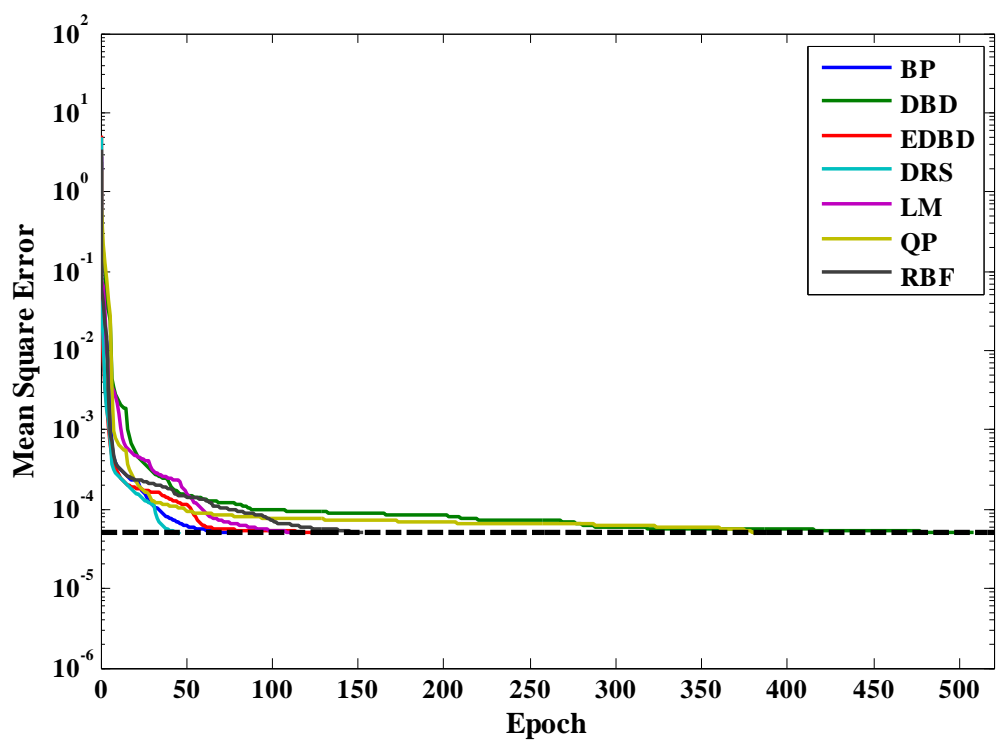

Fig. 12. Squared error against epoch curve for developed ANNs.

Table 1. Specifications of developed ANNs

\begin{tabular}{|l|l|l|}
\hline ANN model & $\begin{array}{l}\text { Number of neurons } \\
\text { in the hidden layer }\end{array}$ & $\begin{array}{l}\text { Training time } \\
\text { [epochs] }\end{array}$ \\
\hline BP & 11 & 77 \\
\hline DBD & 17 & 508 \\
\hline EDBD & 20 & 128 \\
\hline DRS & 15 & 46 \\
\hline LM & 15 & 117 \\
\hline QP & 17 & 381 \\
\hline RBF & 11 & 153 \\
\hline
\end{tabular}

where $\mathrm{OV}_{\mathrm{ANN}}$ is the overvoltage peak calculated by $\mathrm{ANN}$, and $\mathrm{OV}_{\mathrm{PSB}}$ refers to the overvoltage peak calculated by PSB.

The relative error for training and testing sets for $L M$ algorithm is shown in Fig. 13. Also, the results for a sample test data for all developed ANNs are presented in Table 2 and Figs. 14-16. Calculated errors for different ANNs in Table 2 are relative errors. Fig. 14 shows overvoltage peak against the supply voltage, while Fig. 15 presents the overvoltage peak against the stator reactance. Finally, overvoltage peak against the referred rotor reactance is shown in Fig. 16.

\section{Discussion}

In this section a comparison is performed between all developed ANNs to investigate their ability to estimate overvoltage peak during IM starting. Table 2 shows that all developed ANNs can estimate these overvoltages properly. Table 3 presents a comparison between these ANNs from average relative and absolute point of view. In this Table, these errors are calculated for sample data of Table 2. The result shows that LM and EDBD algorithms can evaluate overvoltage peak with better accuracy. Therefore these algorithms are first choice for predicting overvoltage peak during IM starting for manufactures and operators. 

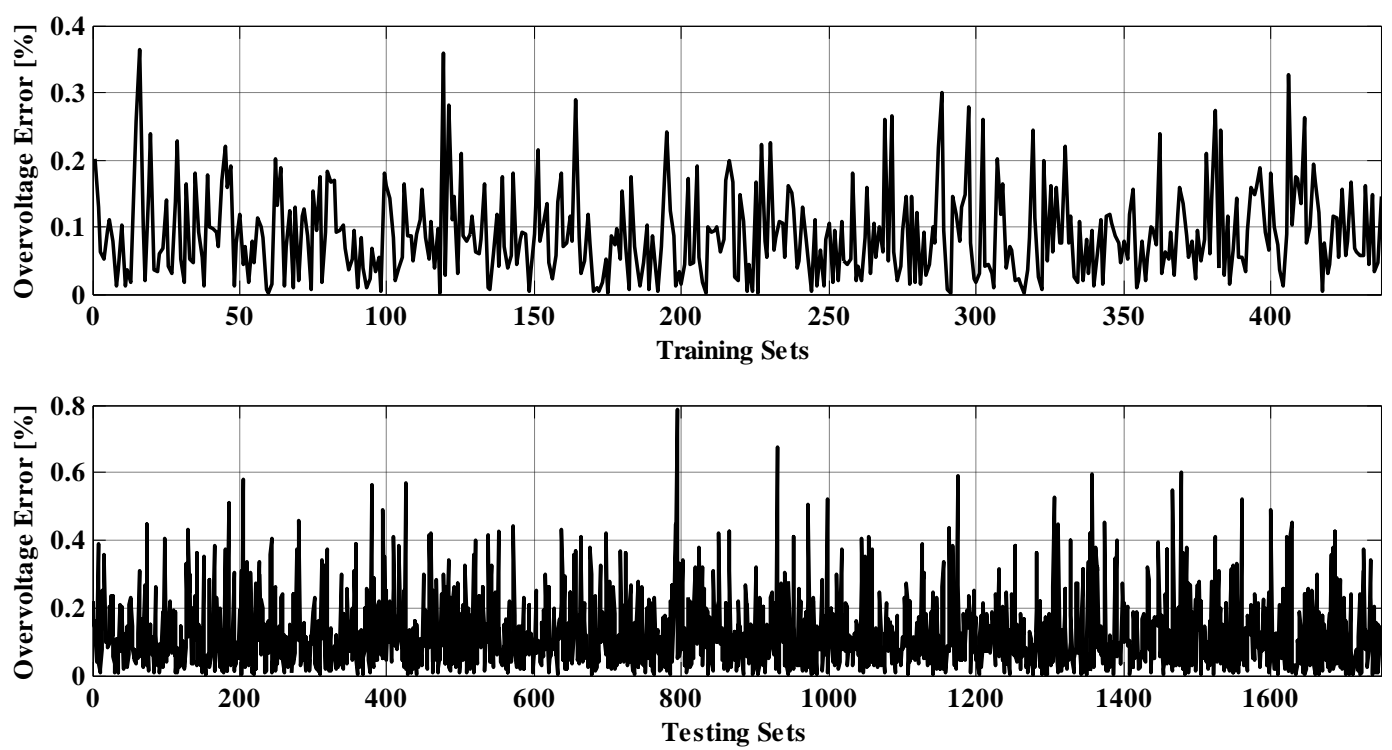

Fig. 13. Relative errors of learning and testing sets for LM algorithm.

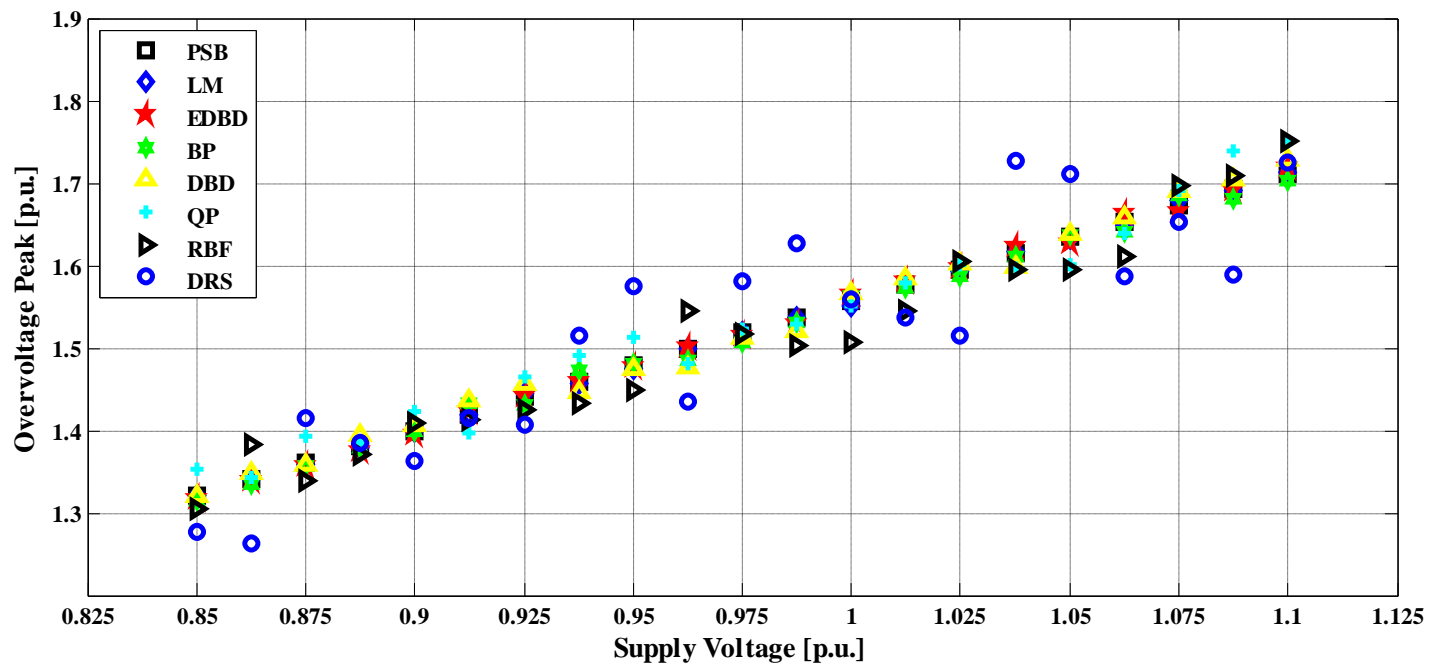

Fig. 14. Overvoltage peak vs. supply voltage simulated by ANNs and PSB while cable resistance 0.01 p.u., cable reactance 0.0314 p.u., cable capacitance $100 \mu \mathrm{F}$, stator reactance 0.14 p.u., referred rotor reactance 0.08 p.u., and switching angle $30^{\circ}$.

\section{Conclusion}

This paper attends one of the PQ disturbances during IM starting. Because of harmful effect of switching overvoltage on the insulation and the locally connected other loads, this phenomenon is studied in this paper. Also, these overvoltages are estimated by ANN. Both MLP and RBF structures have been employed for this purpose. MLP is trained with BP, DBD, EDBD, DRS, QP, and LM algorithms. Effectiveness of this approach is verified by simulation studies. Among all developed ANNs, LM and EDBD algorithms presents better performance. Proposed tool can be used by manufactures and operators during both design and operation stages to predict accurate value of overvoltage peak to adopt proper cautionary measures. 
Table 2. Some sample testing data and output

\begin{tabular}{|c|c|c|c|c|c|c|c|c|c|c|}
\hline 0.95 & 0.95 & 0.95 & 0.95 & 1 & 1 & 1 & 1 & 1.05 & 1.05 & 1.05 \\
\hline 1 & 100 & 100 & 10 & 10 & 10 & 10 & 1 & 1 & 100 & 100 \\
\hline 0.1 & 0.1 & 0.1 & 0.16 & 0.16 & 0.16 & 0.06 & 0.06 & 0.06 & 0.06 & 0.18 \\
\hline 45 & 80 & 80 & 80 & 80 & 25 & 25 & 25 & 55 & 55 & 55 \\
\hline 1.717644 & 1.67326 & 1.441619 & 1.594234 & 1.659036 & 1.78054 & 1.700629 & 1.870158 & 1.792409 & 1.618178 & 1.72525; \\
\hline 1.718721 & 1.675442 & 1.439808 & 1.598089 & 1.660675 & 1.778328 & 1.697848 & 1.875454 & 1.79138 & 1.613185 & $1.72467 \subseteq$ \\
\hline 0.026989 & 0.010309 & 0.340739 & 0.299314 & 0.057015 & 0.398123 & 0.308925 & 0.251068 & 0.034639 & 0.068004 & $0.47444 t$ \\
\hline 1.716743 & 1.670642 & 1.446141 & 1.590177 & 1.662431 & 1.774757 & 1.71178 & 1.873507 & 1.788774 & 1.626522 & 1.72877" \\
\hline 0.052481 & 0.156436 & 0.313679 & 0.254451 & 0.204639 & 0.324812 & 0.655701 & 0.1791 & 0.202851 & 0.515688 & 0.20428 \\
\hline 1.717813 & 1.670984 & 1.439287 & 1.588348 & 1.667455 & 1.78277 & 1.707634 & 1.875832 & 1.813397 & 1.621418 & $1.73581 \varepsilon$ \\
\hline 0.009865 & 0.136016 & 0.161767 & 0.369204 & 0.507494 & 0.125191 & 0.411857 & 0.303404 & 1.170921 & 0.200272 & 0.61242 \\
\hline 1.725915 & 1.668102 & 1.424554 & 1.604909 & 1.654405 & 1.777943 & 1.690434 & 1.853129 & 1.829908 & 1.605933 & $1.72911 \varepsilon$ \\
\hline 3.254908 & 2.629283 & 5.60916 & 3.428183 & 1.344585 & 2.814242 & 1.583876 & 1.621532 & 4.872626 & 3.731673 & 0.76695 \\
\hline
\end{tabular}




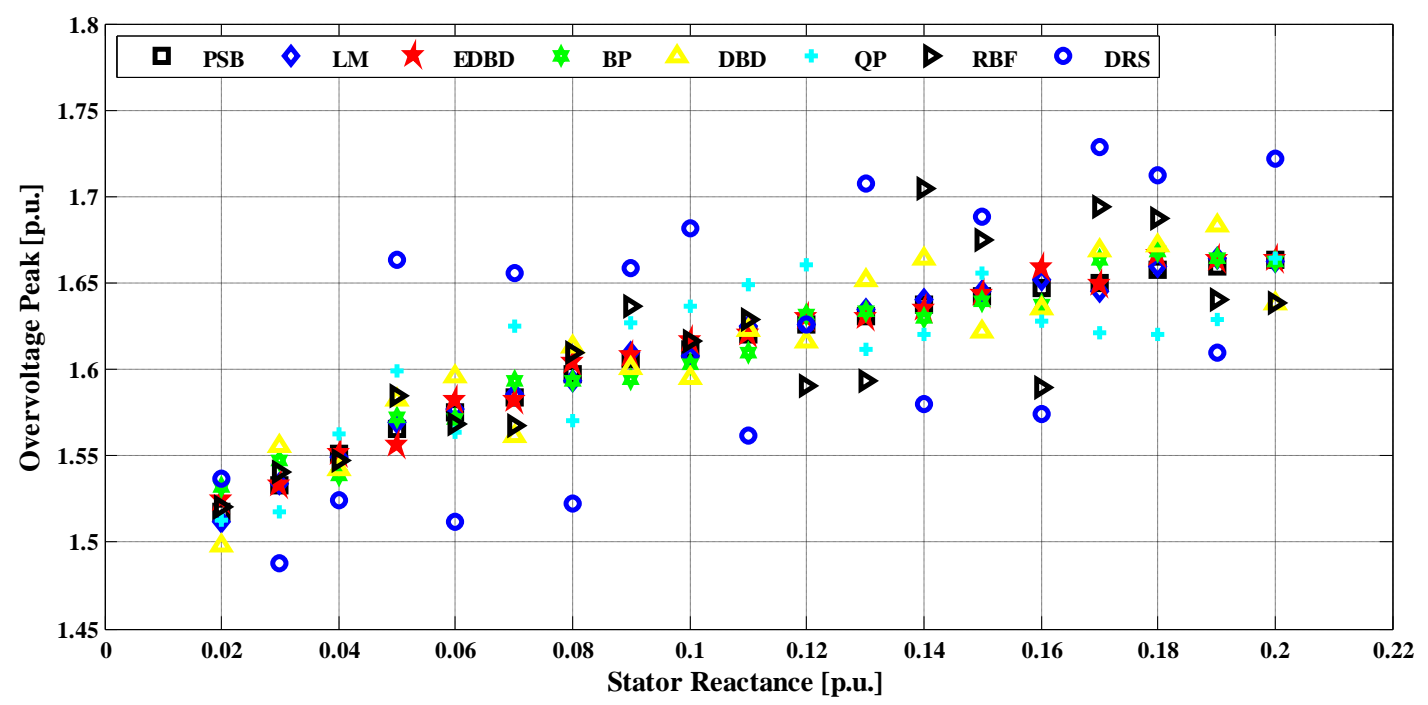

Fig. 15. Overvoltage peak vs. stator reactance simulated by ANNs and PSB while supply voltage 1 p.u., cable resistance 0.01 p.u., cable reactance 0.0188 p.u., cable capacitance $1 \mu \mathrm{F}$, referred rotor reactance 0.1 p.u., and switching angle $60^{\circ}$.

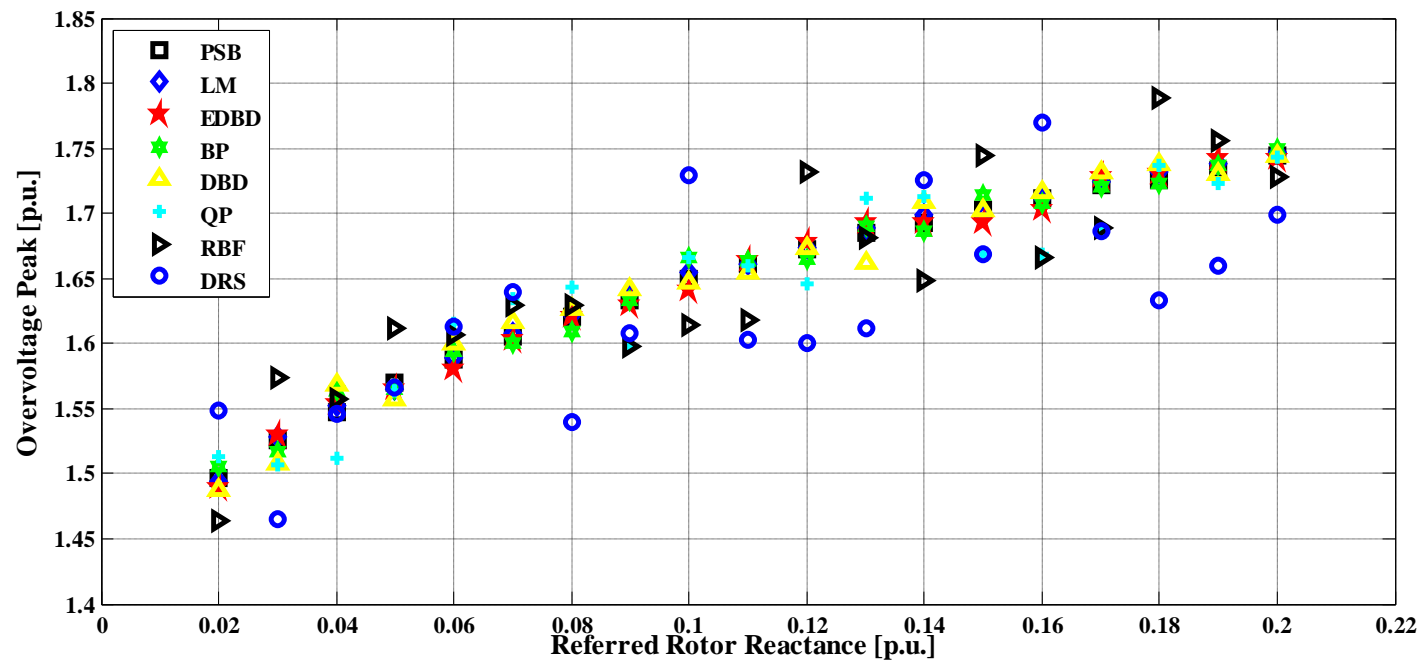

Fig. 16. Overvoltage peak vs. referred rotor reactance simulated by ANNs and PSB while supply voltage 1.05 p.u., cable resistance 0.016 p.u., cable reactance 0.0503 p.u., cable capacitance $10 \mu \mathrm{F}$, stator reactance 0.12 p.u., and switching angle $90^{\circ}$. 
Table 3. Average of relative and absolute errors for Table 2 sample data

\section{Acknowledgement}

\begin{tabular}{|l|l|l|}
\hline ANN Model & $\begin{array}{l}\text { Average of relative } \\
\text { peak error [\%] }\end{array}$ & $\begin{array}{l}\text { Average of } \\
\text { absolute peak } \\
\text { error [p.u.] }\end{array}$ \\
\hline BP & 0.2622 & 0.0044 \\
\hline DBD & 0.3695 & 0.0064 \\
\hline EDBD & 0.1930 & 0.0033 \\
\hline DRS & 2.8448 & 0.0477 \\
\hline LM & 0.1487 & 0.0025 \\
\hline QP & 0.6875 & 0.0117 \\
\hline RBF & 1.1942 & 0.0205 \\
\hline
\end{tabular}

This work has been supported by the Iran's National Elites Foundation.

\section{References}

[1] G. Lee, S. Min, J.P. Hong, Optimal Shape Design of Rotor Slot in Squirrel-Cage Induction Motor Considering Torque Characteristics, IEEE Transactions on Magnetics, vol.49, (2013) no.5, 21972200.

[2] S.S. Sivaraju, F.J.T.E. Ferreira, N. Devarajan, Genetic algorithm based design optimization of a three-phase multiflux Induction Motor, 2012 XXth International Conference on Electrical Machines (ICEM), Marseille (2012) 288-294.

[3] A.S. Vizhi, S. Nagarajan, S. Ramareddy, Detection and analysis of broken bar in three phase squirrel cage induction motor using FEM, International Conference on Computing, Electronics and Electrical Technologies (ICCEET), Kumaracoil (2012) 40-50.

[4] [Online]. Available: www.ece.msstate.edu/ donohoe/ece3614induction_machines_I.pdf.

[5] A. Foroughi, E. Mohammadi, S. Esmaeili, Application of HH-transform and support vector machine for detection and classification of voltage sag sources, Turkish Journal of Electrical Engineering \& Computer Sciences, to be published.

[6] J.V. Milanovic, M.T. Aung, S.C. Vegunta, The Influence of Induction Motors on Voltage Sag Propagation-Part I: Accounting for the Change in Sag Characteristics, IEEE Transactions on Power Delivery. 23 (2008) 1063-1071.

[7] M.Z. El-Sadek, N.H. Fetih, F.N. Abdelbar, Starting of induction motors by static VAR compensators, Third International Conference on Power Electronics and Variable-Speed Drives, London (1988) 444-447.

[8] L. Wang, C.N.-m. Ho, F. Canales, J. Jatskevich, High-Frequency Modeling of the Long-Cable-Fed Induction Motor Drive System Using TLM Approach for Predicting Overvoltage Transients, IEEE Transactions on Power Electronics. 25 (2010) 2653-2664.

[9] B. Basavaja, D.V.S.S. Siva Sarma, Modelling, Simulation and Experimental Analysis of Transient Terminal Overvoltage in PWM-Inverter fed Induction Motors, IEEE Power Engineering Society General Meeting, Tampa (2007) 1-8. 
[10] A. Hellany, H. Achi, Over-voltage on inverter fed induction motor drive system, in Proc. 10th IEEE International Conference on Electronics, Circuits and Systems, ICECS 2003, 2 (2003) 846-849 Vol.2.

[11] P. C. Krause, O. Wasynczuk, S. D. Sudhoff, and S. Pekarek, Analysis of Electric Machinery and Drive Systems. $3^{\text {rd }}$ Edition, Wiley-IEEE Press, 2013.

[12] I. Sadeghkhani, A. Ketabi, and R. Feuillet, Investigation of Transmission Line Models for Switching Overvoltages Studies, International Journal of Emerging Electric Power Systems. 14 (2013) 231238.

[13] [Online]. Available: www.valiadis.gr/pool/ftp/drawings/KHV3552_200KW_3300V_TEST_REPORT.pdf.

[14] P.C. Sen, Principles of Electric Machines and Power Electronics. $2^{\text {nd }}$ Edition, John Willey, 1997.

[15] A. Ketabi and I. Sadeghkhani, Electric Power Systems Simulation Using MATLAB. $2^{\text {nd }}$ Edition, Morsal Publications, Kashan, Iran, 2012. (in Persian)

[16] C. Yildiz, S. Gultekin, K. Guney, and S. Sagiroglu, Neural Models for the Resonant Frequency of Electrically Thin and Thick Circular Microstrip Antennas and the Characteristic Parameters of Asymmetric Coplanar Waveguides Backed with a Conductor, AEU - International Journal of Electronics and Communications. 56 (2002) 396-406.

[17] I. Sadeghkhani and A. Ketabi, Switching Overvoltages during Restoration: Evaluation and Control Using ANN. Lambert Academic Publishing, Köln, Germany, 2012.

[18] H.C. Chiu, M. Honarmand, E. Sanjari, H. Badihi, Prediction of saturated vapor pressures using non-linear equations and artificialneuralnetwork approach, The Journal of Mathematics and Computer Science. 8 (2014) 343 - 358.

[19] A. Ketabi, I. Sadeghkhani, and R. Feuillet, Using Artificial Neural Network to Analyze Harmonic Overvoltages during Power System Restoration, European Transactions on Electrical Power. 21 (2011) 1941-1953.

[20] A. Ketabi, I. Sadeghkhani, and R. Feuillet, Network Switching and Voltage Evaluation during Power System Restoration, Electrical Engineering (Archiv fur Elektrotechnik). 95 (2013) 241-253.

[21] H. Ravaee, S. Farahat, F. Sarhaddi, Artificial Neural Network Based Model of Photovoltaic Thermal (PVT) Collector, The Journal of Mathematics and Computer Science.4 (2012) 411 417.

[22] S.A. Taher and I. Sadeghkhani, Estimation of Magnitude and Time Duration of Temporary Overvoltages using ANN in Transmission Lines during Power System Restoration,Simulation Modelling Practice and Theory.18 (2010) 787-805.

[23] S. Ayat, Z. Ahmad Pour, Comparison between ArtificialNeuralNetwork Learning Algorithms for Prediction of Student Average considering Effective Factors in Learning and Educational Progress, The Journal of Mathematics and Computer Science.8 (2014) $215-225$.

[24] I. Sadeghkhani, A. Ketabi, and R. Feuillet, Control of Shunt Reactor Overvoltages by Controlled Switching during Power System Restoration, Journal of Circuits, Systems, and Computers. 21 (2012) 1-15.

[25] M.T. Hagan and M.B. Menhaj, Training feedforward networks with the Marquardt algorithm, IEEE Trans. Neural Network. 5 (1994) 989-993. 